\title{
Retinal oximetry using ultrahigh-resolution optical coherence tomography
}

This article was published in the following Dove Press journal:

Clinical Ophthalmology

II December 2012

Number of times this article has been viewed

\author{
Yufeng $\mathrm{Ye}^{1,2}$ \\ Hong Jiang 2,3 \\ Meixiao Shen ${ }^{4}$ \\ Byron L Lam² \\ Delia Cabrera DeBuc ${ }^{2}$ \\ Lili $\mathrm{Ge}^{2,4}$ \\ Mitra Sehi ${ }^{2}$ \\ Jianhua Wang ${ }^{2}$ \\ 'Hangzhou First People's Hospital, \\ Hangzhou, China; ${ }^{2}$ Bascom Palmer \\ Eye Institute, ${ }^{3}$ Neurology, University \\ of Miami, Miami, FL, USA; ${ }^{4}$ School \\ of Ophthalmology and Optometry, \\ Wenzhou Medical College, Wenzhou, \\ Zhejiang, China
}

Correspondence: Hong Jiang

Bascom Palmer Eye Institute, University of Miami, Miller School of Medicine, 1638 NW 10th Avenue, McKnight Building, Room 202A, Miami,

FL 33। 36, USA

$\mathrm{Tel}+\mathrm{I} 3054825010$

Fax

Email hjiang@med.miami.edu
Background: The purpose of this study was to investigate the repeatability of retinal oximetry using slit-lamp adapted ultrahigh-resolution optical coherence tomography (SL-UHR-OCT).

Methods: SL-UHR-OCT was developed and fringe patterns were obtained for a major retinal artery and a major retinal vein. A-scans at the central wavelengths of $805 \mathrm{~nm}$ and $855 \mathrm{~nm}$ were analyzed for calculating optical density ratios (ODRs), from which the percentage oxygen saturation was calculated. Measurements were made on two occasions for each person. Repeatability and coefficients of repeatability were calculated.

Results: The mean ODRs of the artery were $0.79 \pm 0.86$ and $0.88 \pm 0.97$ in sessions 1 and 2, respectively. The mean ODRs of the vein were $-0.08 \pm 0.69$ and $0.14 \pm 0.77$ between the two sessions, and were significantly lower than that of the artery $(P<0.05)$. The coefficients of repeatability were 1.44 and 1.81 for the artery and vein, respectively. The mean oxygen saturation of the major retinal artery was $94 \% \pm 45 \%$ and $98 \% \pm 51 \%$ in sessions 1 and 2 , respectively, and the mean oxygen saturation of the major retinal vein was $48 \% \pm 36 \%$ and $60 \% \pm 40 \%$ between sessions.

Conclusion: Optical coherence tomographic oximetry for evaluating retinal oxygen saturation was subject to variation, although the averaged measurements in repeated sessions were matched. Further work on reducing variation will be needed.

Keywords: ultrahigh-resolution optical coherence tomography, oximetry

\section{Introduction}

Retinal oxygen saturation is a measure of the metabolic state of the retina. Many ocular diseases, including diabetic retinopathy, ${ }^{1-8}$ glaucoma, ${ }^{9-11}$ and retinal vein occlusion, ${ }^{12,13}$ result in altered retinal blood flow and oxygen saturation. A reliable method of measuring retinal oxygen saturation would be beneficial for studying, monitoring, and managing these disorders. Retinal oximetry devices based on spectral image analysis through a fundus camera system have been developed for imaging retinal oxygen saturation. However, commercially available systems have not been used widely in clinics, possibly due to their high cost, lack of US Food and Drug Administration clearance, and insufficient clinical studies to justify their routine use in clinics. ${ }^{14-17}$ Optical coherence tomography (OCT) is an advanced imaging modality in ophthalmology and provides high-resolution imaging of retinal structures. Kagemann et al ${ }^{18}$ have demonstrated that spectral data in images captured by ultrahigh-resolution optical coherence tomography (UHR-OCT) provide useful information for retinal oximetry. They detected a statistically significant difference in oxygen saturation between the major retinal artery and the major retinal vein. The measurement of oxygen saturation 
was based on the principle of differences in the absorption spectra for oxyhemoglobin and deoxyhemoglobin. ${ }^{18,19}$ Their experiments demonstrated that spectral data in UHR-OCT might greatly extend the usefulness of OCT, and therefore, UHR-OCT-based retinal oximetry may be an alternative to fundus camera-based retinal oximetry. The advantage of UHR-OCT retinal oximetry is the simultaneous imaging of the retinal structure and measurement of retinal oxygen saturation. This extension of the capabilities of OCT has the potential to improve further both ophthalmic research and patient care. Before extensive trials of OCT oximetry can be undertaken, it is necessary to determine how repeatable the measurements are. There is no information available on repeatability using OCT oximetry. We have adapted slit-lamp ultrahigh-resolution optical coherence tomography (SL-UHR-OCT) for facilitating retinal imaging. ${ }^{20}$ With the development of a spectral analysis algorithm for retinal oximetry, the goal of the present study was to assess the feasibility and repeatability of OCT-based retinal oximetry in healthy subjects.

\section{Materials and methods}

OCT retinal oximetry was performed using our newly developed SL-UHR-OCT, which was connected to an advanced optical delivery system for retinal imaging, as detailed elsewhere. ${ }^{20}$ Briefly, the system has approximately $3 \mu \mathrm{m}$ depth resolution and a computer-controlled fixation target. A light source
(T840, Superlum Diodes Ltd, Moscow, Russia) with a central wavelength of $840 \mathrm{~nm}$ and a bandwidth of $100 \mathrm{~nm}$ was used. Variability of the OCT light power output depends on the light source. The variability was stable and fixed over time. A spectrometer with a charge-coupled device camera collected reflected fringes. In the sample arm, an X-Y galvanometer scanner was mounted on a standard slit-lamp (Reichart, XCEL 250, Depew, NY). The power of the incident light was within the safety standards set by the American National Standards Institute (ANSI Z136.1-2000). To scan the retina, an ocular lens (60D, Volk Optical, Mentor, $\mathrm{OH}$ ) was placed in front of the eye. The scan speed of the system was set to 24,000 A-scans per second, and the duration of data acquisition for a single dataset was 2.7 seconds. No compensation of eye movement was used. The field of the scan was set to a width of $6 \mathrm{~mm}$, which corresponded to a retinal field of approximately 15-20 degrees. Raster scans were performed to obtain optic disk-centered image frames encompassing a $6 \times 6 \mathrm{~mm}$ slice of retinal tissue (Figure 1A). Each frame consisted of 512 axial scans with 1365 points/A-scan, taking a total of 128 frames. OCT fundus images (en face view) were reconstructed from the acquired three-dimensional dataset, and the retinal veins and arteries were identified.

Data processing and calculation of oxygen saturation were similar to that reported in the pioneer work by Kagemann et al. ${ }^{18}$ To obtain the light intensity at an oxygen-sensitive wavelength $(855 \mathrm{~nm})$ as well as the isosbestic wavelength
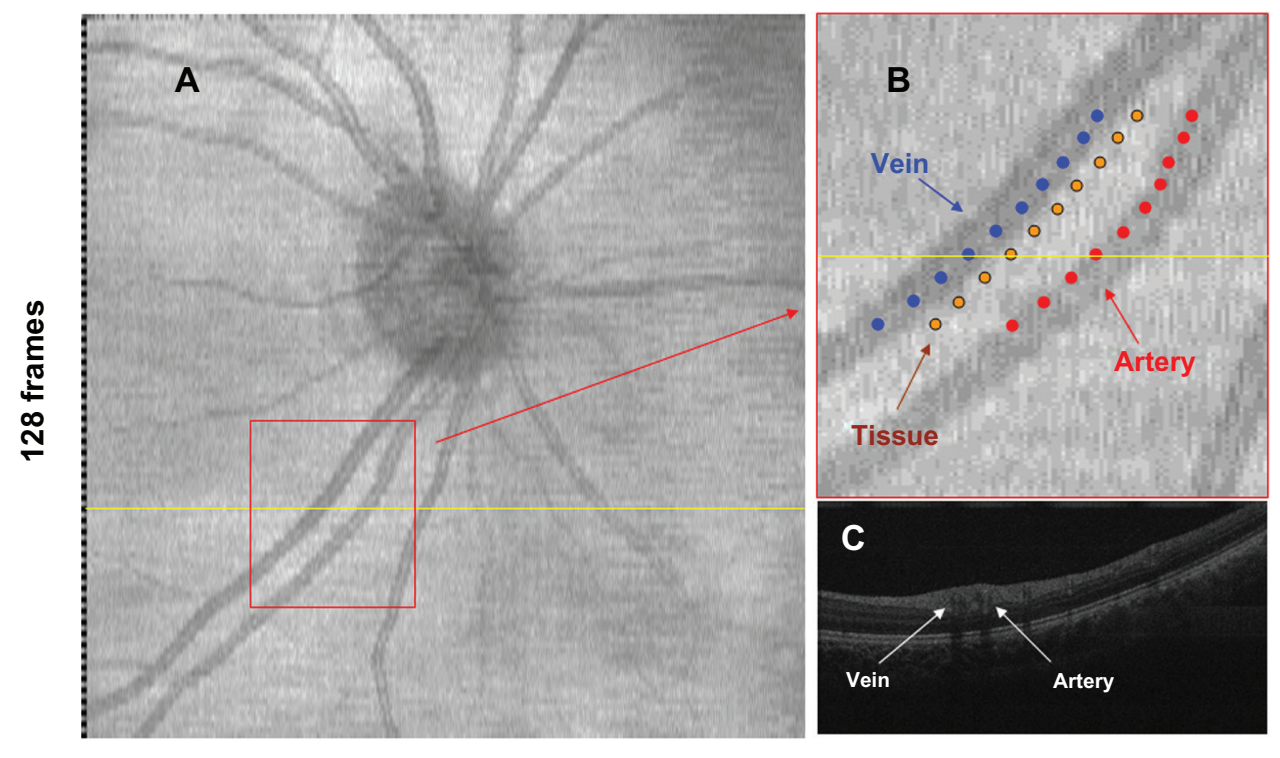

512 A-scans

Figure I OCT images obtained with SL-UHR-OCT. An OCT fundus image that was reconstructed from an OCT dataset (A). The identified vein, artery and tissue were shown on the enlarged fundus image (B); ten fringe images at the locations with marked dots were sampled from the artery, vein and tissue to calculate the optical densities. OCT B-scan image (C) across the sampled range was from the scan marked with the yellow line in image $A$.

Abbreviations: OCT, optical coherence tomography; SL-UHR-OCT, slit-lamp adapted ultrahigh-resolution optical coherence tomography. 
$(805 \mathrm{~nm})$, the spectrum of the light source in our UHR-OCT was first calibrated to identify the pixel location of each wavelength on the charge-coupled device. A customized code written in Matlab (MathWorks Inc, version 7.3) was developed to recalculate the light intensity of the A-scans from the sampled unprocessed fringe after subtracting the background. Ten fringe patterns were sampled at the side of the optic nerve head from the edge of a major (first degree) artery, adjacent tissue, and the edge of a major vein. A total of 95 pixels within a $10 \mathrm{~nm}$ range of each wavelength of interest ( $805 \mathrm{~nm}$ and $855 \mathrm{~nm}$, respectively) of the OCT light spectrum was sampled (Figure 2). The sampled data were then processed by resampling, dispersion compensation, fast Fourier transform, and magnitude computation to obtain the intensity profile of the locations. The intensity of the entire A-scan was summed as the light intensity of the wavelength of interest. Optical densities and optical density ratios (ODRs) for each of the 10 measurements were calculated and then averaged. The calculation of optical densities (OD) and ODRs for each vessel was as follows:

$$
\begin{gathered}
\mathrm{OD}_{\lambda}=\ln \left(\frac{\mathrm{I}_{\lambda 0}}{\mathrm{I}_{\lambda}}\right), \\
\mathrm{ODR}_{\lambda}=\frac{\mathrm{OD}_{\text {sensitive }}}{\mathrm{OD}_{\text {isobestic }}},
\end{gathered}
$$

In equation $1, I_{\lambda}$ and $I_{\lambda 0}$ are the average pixel values inside and immediately adjacent, respectively, to a blood vessel when illuminated at wavelength $\lambda$. In equation $2, \mathrm{OD}$ and $\mathrm{OD}_{\text {isosbestic }}$ are optical densities at oxygen-sensitive and oxygen-insensitive wavelengths. The percent hemoglobin oxygen saturation $\left(\mathrm{SO}_{2}\right)$ is linearly proportional to the ODRs, and expressed as follows (equation 3):

$$
\mathrm{SO}_{2}=\mathrm{a}+\mathrm{b}^{*} \mathrm{ODR}
$$

where $\mathrm{a}$ and $\mathrm{b}$ are constants. In addition, retinal oxygen use (ODR of the artery-vein) was calculated as the difference between the oxygen saturation of the major retinal artery and the major retinal vein outside the optic nerve head. To calibrate and convert ODR to oxygen saturation, we used a method similar to that previously used by Hardarson et al, ${ }^{15}$ based on the mean of oxygen saturation for arterioles (96\%) and venules (54\%). The results of all 20 subjects (two measurements from one eye of each subject) were used. Solving equation 3 gave the results of a and $b$, which were used to convert ODR to oxygen saturation.

This study was approved by the institutional review board of the University of Miami and was conducted in accordance with the tenets of the Declaration of Helsinki and the privacy and security regulations of The Health Insurance Portability and Accountability Act of 1996. Informed consent was

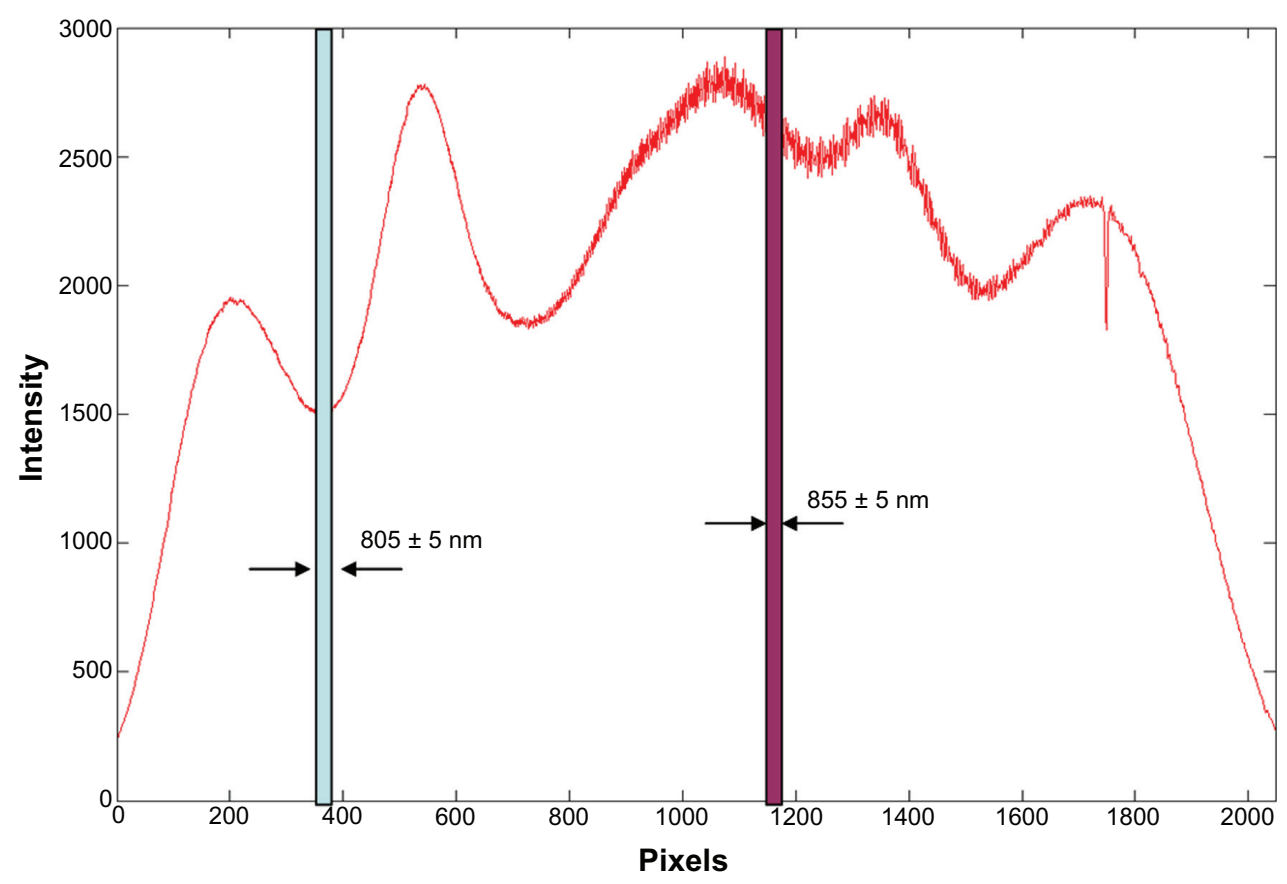

Figure 2 Spectrum of the light source of the slit-lamp adapted ultrahigh-resolution optical coherence tomography.

Notes: Calibrated pixel locations on the charge-coupled camera for wavelengths of $805 \pm 5 \mathrm{~nm}$ and $855 \pm 5 \mathrm{~nm}$ were identified. The fringe from these pixels was processed for calculating the optical intensity of the major retinal artery and vein. 
obtained from each of the study participants. Twenty normal subjects ( 15 women and five men, mean age $37.7 \pm 9.4$ years) were recruited for participation, including 10 Asian subjects, eight Caucasian subjects, and two African-American subjects. Inclusion criteria included best-corrected visual acuity of 20/20 or better, no history of ocular or systematic disease, no history of ocular surgery or laser, and normal appearance of the macula and optic disc. All subjects underwent visual acuity testing, complete slit-lamp biomicroscopic examination, and ophthalmoscopic examination. One randomly selected eye from each subject was scanned twice, with an interval of several minutes between the measurements. During image acquisition, the subjects were asked to place their chin on the chin rest of the slit-lamp and to look at the fixation target. The room lighting was dimmed, and the subject's pupils were not dilated. OCT images were acquired and analyzed to obtain the results. To standardize the image acquisition procedure, image acquisition was conducted for all the subjects and data analysis was performed by the first author. If apparent artifacts occurred due to eye movement, the imaging procedure was repeated. During imaging alignment, the subject was asked to blink normally then hold the eye open during acquisition.

The data are presented as the mean \pm standard deviation. Measurements were compared using the two-tailed pairedsamples $t$-test. $P<0.05$ was considered to be statistically significant. The statistical analysis was performed using Statistical Package for the Social Sciences software version 16 (SPSS Inc, Chicago, IL). The methods outlined by Bland and Altman ${ }^{21}$ were used to assess the agreement between measurements taken during the two sessions. Coefficients of repeatability of the ODRs were calculated. The coefficient of repeatability is a measure of the $95 \%$ limit of agreement, as proposed originally by Bland and Altman, ${ }^{21}$ and adopted by the International Organization for Standardization; it is calculated as the mean $\pm 1.96 \times$ the standard deviation of the difference between repeated measurements obtained from the same subject by the same observer.

\section{Results}

The retinal image-based datasets of 20 eyes from 20 healthy subjects were successfully acquired using OCT oximetry, and en face views of the scan area were reconstructed (Figure 1). The mean ODRs of the major retinal artery were $0.79 \pm 0.86$ and $0.88 \pm 0.97$ in sessions 1 and 2 , respectively, and the mean ODRs of the major retinal vein were $-0.08 \pm 0.69$ and $0.14 \pm 0.77$ in sessions 1 and 2 , respectively (Table 1). Mean ODR values for artery-vein were $0.87 \pm 1.06$ and $0.74 \pm 1.14$ in sessions 1 and 2, respectively. There were significant differences in the ODRs of the major retinal artery and the major retinal vein in both sessions ( $P=0.002$, session $1 ; P=0.009$ session 2$)$. There were no significant differences in the ODRs for the major retinal artery, major retinal vein, and oxygen use $(P=0.581$, $P=0.302$, and $P=0.621$, respectively) between the two sessions. The coefficient of repeatability was 1.44 for the retinal artery and 1.81 for the retinal vein. Intraclass correlation coefficients were calculated to measure the agreement of each measurement. The 95\% limit of agreement and intraclass correlation coefficients are shown in Table 1.

Calibration from 20 eyes for OCT oximetry gave $a=52.3$ and $b=52.1$, and the conversion equation for oxygen saturation $\left(\mathrm{SO}_{2}\right)$ is

$$
\mathrm{SO}_{2}=52.3+52.1 * \mathrm{ODR}
$$

Mean oxygen saturation of the major retinal artery was $94 \% \pm 45 \%$ and $98 \% \pm 51 \%$ in sessions 1 and 2 , respectively, and the mean ODR of the major retinal vein was $48 \% \pm 36 \%$ and $60 \% \pm 40 \%$ in sessions 1 and 2 , respectively (Table 1). There were no significant differences between oxygen saturation in the major retinal artery, the major retinal vein, and oxygen use $(P>0.05)$ between the two sessions. Bland-Altman plots of difference against mean oxygen saturation of the artery, vein, and artery-vein measurements from the two sessions are shown in Figure 3.

\section{Discussion}

The retina is one of the most active metabolic tissues in the body, and adequate oxygen circulation is necessary for maintaining retinal health. Numerous attempts have been made to develop methods for measuring oxygen availability in the retinal tissue and vasculature. Direct measurements of oxygen pressure in the retina outside the retinal vessels or close to the vessels have been used to determine whether a supply deficit exists. ${ }^{22-24}$ Some studies have measured oxygen pressure using an oxygen-sensitive electrode. ${ }^{22-25}$ However, these methods are invasive, so are only used in animal experiments ${ }^{22,23}$ or during intraocular surgery in human studies. ${ }^{24}$ Another way to measure the retinal oxygen supply is based on differences in the absorption spectra of oxygenated and deoxygenated hemoglobin. Several human retinal oximetry devices based on spectral imaging of the fundus with two wavelengths or with multiple wavelengths

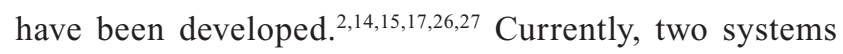
to measure retinal oxygen saturation are commercially available, ie, a retinal oximeter (Oxymap, ehf, Reykjavik, 
Table I Retinal oxygen saturation measured with ultrahigh-resolution optical coherence tomography $(n=20)$

\begin{tabular}{|c|c|c|c|c|c|c|c|}
\hline $\begin{array}{l}\text { ODR } \\
\mathrm{SO}_{2}(\%) \\
\end{array}$ & Session I & Session 2 & $\begin{array}{l}\text { Mean } \\
(\mathrm{S} 1 \mathrm{~S} 2) / 2\end{array}$ & $\begin{array}{l}\text { Difference } \\
\text { S1 - S2 } \\
\end{array}$ & $\begin{array}{l}95 \% \text { limit of } \\
\text { agreement" }\end{array}$ & CR & ICC \\
\hline Artery & $\begin{array}{l}0.79 \pm 0.86 \\
(94 \pm 45)\end{array}$ & $\begin{array}{l}0.88 \pm 0.97 \\
(98 \pm 5 I)\end{array}$ & $\begin{array}{l}0.84 \pm 0.84 \\
(96 \pm 44)\end{array}$ & $\begin{array}{l}-0.09 \pm 0.73 \\
(-5 \pm 38)\end{array}$ & $\begin{array}{l}-1.56 \text { to }+1.37 \\
(-81 \text { to } 72)\end{array}$ & $\begin{array}{l}1.44 \\
(75)\end{array}$ & 0.680 \\
\hline Vein & $\begin{array}{l}-0.08 \pm 0.69 \\
(48 \pm 36)\end{array}$ & $\begin{array}{l}0.14 \pm 0.77 \\
(60 \pm 40)\end{array}$ & $\begin{array}{l}0.03 \pm 0.56 \\
(54 \pm 29)\end{array}$ & $\begin{array}{l}-0.22 \pm 0.92 \\
(-11 \pm 48)\end{array}$ & $\begin{array}{l}-2.06 \text { to }+1.63 \\
(-107 \text { to } 85)\end{array}$ & $\begin{array}{l}1.81 \\
(94)\end{array}$ & 0.196 \\
\hline Artery-vein & $\begin{array}{l}0.87 \pm 1.06 \\
(45 \pm 55)\end{array}$ & $\begin{array}{l}0.74 \pm 1.14 \\
(39 \pm 59)\end{array}$ & $\begin{array}{l}0.81 \pm 0.94 \\
(42 \pm 49)\end{array}$ & $\begin{array}{l}0.13 \pm 1.13 \\
(7 \pm 59)\end{array}$ & $\begin{array}{l}-2.13 \text { to }+2.38 \\
(-111 \text { to } 124)\end{array}$ & $\begin{array}{l}2.21 \\
(115)\end{array}$ & 0.473 \\
\hline
\end{tabular}

Note: $* 95 \%$ limit of agreement is calculated as the mean $\pm 1.96 \times$ SD of the difference between repeated measurements obtained from the same subject by the same observer.

Abbreviations: CR, coefficients of repeatability; ICC, intraclass correlation coefficient; ODR, optical density ratio (mean \pm SD); SO $\%$, oxygen saturation (mean \pm SD, \%); SI, session I; S2, session 2; SD, standard deviation.

Iceland) ${ }^{6,12-15,28,29}$ and a retinal vessel analyzer (DVA, Imedos Systems UG Jena, Germany). ${ }^{30,31}$ Although oximetry devices are increasingly being used for research, none of these systems are widely available for routine clinical use, possibly due to high costs, ${ }^{14,15,17}$ lack of clearance by the Food and Drug Administration, and lack of sufficient clinical studies to justify their routine use in clinics.

OCT is used widely in both clinical and research settings..$^{20,32,33}$ High-resolution images of both the anterior and posterior structures of the eye can be obtained. ${ }^{34,35}$ New capabilities of functional imaging using OCT have recently been developed..$^{17,32,36}$ For example, Kagemann et a ${ }^{18}$ explored the possibility of retinal oximetry using spectral analysis from UHR-OCT retinal images, and Enfield et $\mathrm{al}^{36}$ explored in vivo imaging of the microcirculation of the skin. In the present study, we tested the repeatability of measuring retinal oxygen saturation in healthy subjects with our newly developed SL-UHR-OCT. The approach was based on the work of Kagemann et al. ${ }^{18}$

\section{A}

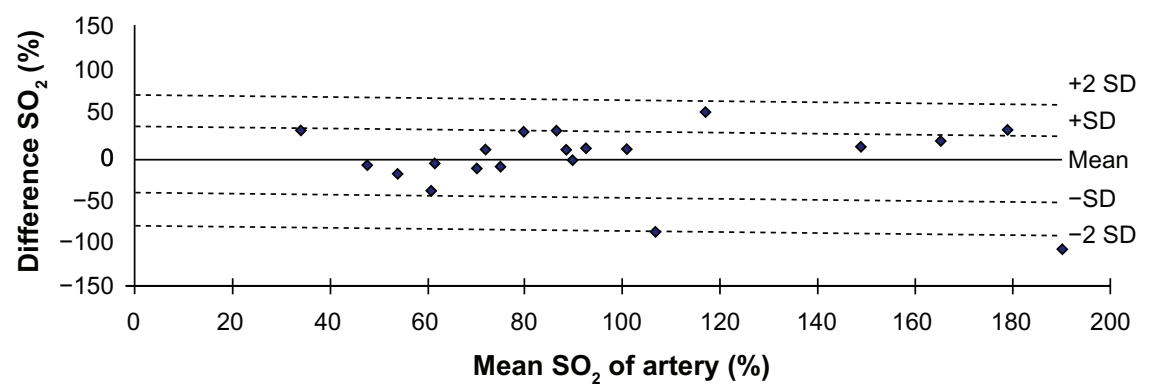

B
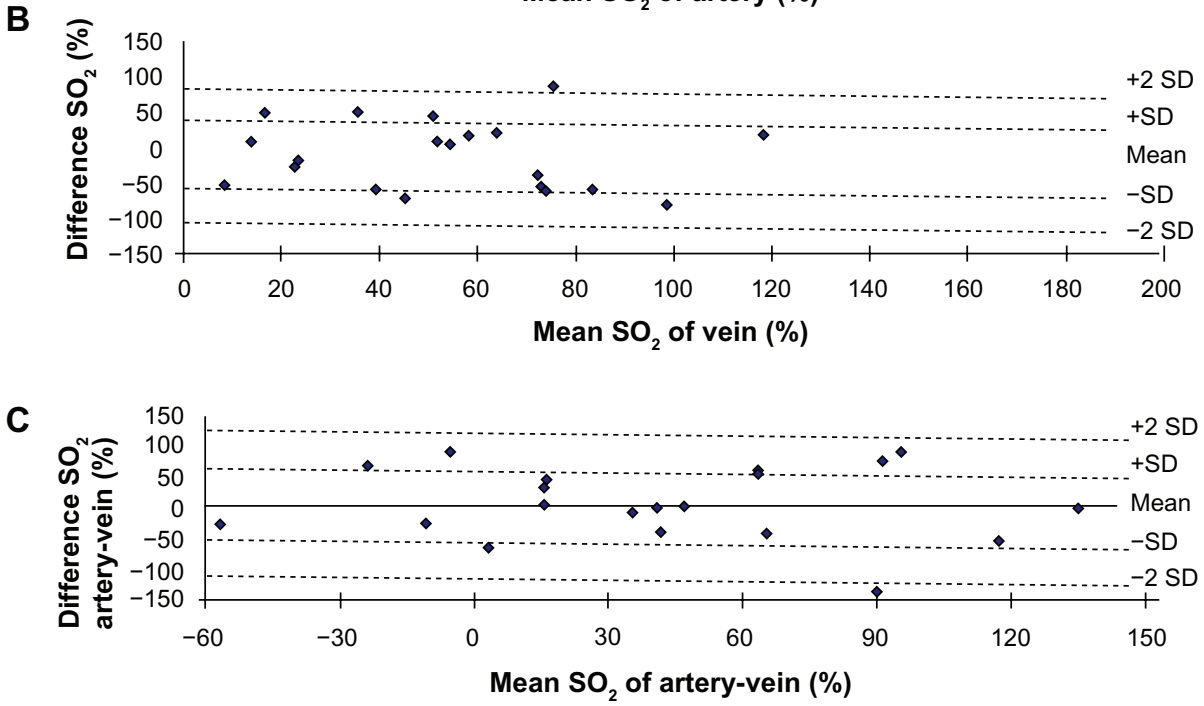

Figure 3 Bland-Altman plot of the difference between two measurements. The plots of mean artery $\mathrm{SO}_{2}(\mathbf{A})$, vein $\mathrm{SO}_{2}(\mathbf{B})$, and artery-vein $\mathrm{SO}_{2}(\mathbf{C})$ against differences in optical density ratio obtained during two sessions of $\mathrm{SO}_{2}$ measurements in 20 healthy subjects.

Note: Solid lines and dashed lines indicate mean differences and $95 \%$ limits of agreement.

Abbreviations: $\mathrm{SO}_{2}$, oxygen saturation; $\mathrm{SD}$, standard deviation. 
In the present study, the light source for SL-UHR-OCT had a $100 \mathrm{~nm}$ bandwidth with a central wavelength of $840 \mathrm{~nm}$, which included both an oxygen-sensitive wavelength $(855 \mathrm{~nm})$ and an isosbestic wavelength $(805 \mathrm{~nm})$. Our work was based on the assumption that there is a distinct difference in the spectrum of arteries and of that in veins, that is due to the fact that arteries and veins have different proportions of oxyhemoglobin and deoxyhemoglobin. As expected, we found a significantly higher oxygen saturation in the artery than in the vein in the healthy group.

Information about the measurement repeatability of a developing method like OCT retinal oximetry is important for calculating appropriate study sample sizes in future studies. ${ }^{37}$ In the present study, there were obvious variations in artery ODR, vein ODR, and artery-vein ODR. The coefficients of repeatability were $1.44,1.81$, and 2.21 for arterial, venous, and artery-vein ODR values, respectively. However, it should be mentioned that there were no significant differences between the mean ODRs measured in the two sessions. Similar results have been reported by Kagemann et al. ${ }^{18}$ This phenomenon may indicate a relatively higher variability of this technique, which results in a need for a large sample size for detecting significant changes in oxygen saturation. For example, up to 40 subjects would be needed to detect an increase of $23 \%$ in venular oxygen saturation during inhalation of pure oxygen using OCT oximetry, ${ }^{38}$ according to a software program (Gpower, version 3.0) developed by Erdfelder et al. ${ }^{39}$ Further improvement will be needed before this method can be used routinely in clinic. ${ }^{38}$

The standard deviations in this study were larger than those reported in previous studies based on spectral imaging systems for the fundus. Hardarson et a ${ }^{15}$ reported considerably smaller standard deviations for retinal oxygen saturation in their group as a whole ( $9 \%$ in arteries and $14 \%$ in venules) in healthy subjects when they inhaled $21 \% \mathrm{O}_{2}$ (ambient air). The standard deviations of five repeated measurements in a group of 10 subjects inhaling room air were $3.7 \%$ and $5.3 \%$ in the artery and vein measurements, respectively. They also found that data based on wavelengths of $586 \mathrm{~nm}$ and $605 \mathrm{~nm}$ were more reproducible than data based on $542 \mathrm{~nm}$ and $558 \mathrm{~nm}$ for artery and vein measurements, respectively. Hammer et al ${ }^{16}$ used a fundus camera that can record two monochromatic fundus images at $548 \mathrm{~nm}$ and $610 \mathrm{~nm}$ simultaneously. Arterial and venous oxygen saturations were $98 \% \pm 10.1 \%$ and $65 \% \pm 11.7 \%$, respectively. For measurements in the same segments of arteries and veins from five images per subject, standard deviations of $2.52 \%$ and $3.25 \%$ were found for oxygen saturation in the arteries and veins, respectively.
They also found that venous oxygen saturation varied in individuals with different iris colors and that iris color is a good estimate of fundus pigmentation. ${ }^{16}$

The benefit of the UHR-OCT method for retinal oximetry is that it combines structural and functional imaging, thereby yielding simultaneous information about retinal layer thickness and oximetry. This may be very helpful in studying and correlating retinal lesions with oxygen supply/use. Further developments in three-dimensional mapping of oxygen saturation and microcirculation similar to the work using OCT to image microcirculation in the skin will make the method more useful. The large variability of this method compared with fundus camera-based retinal oximetry may be attributed to the nature of OCT data acquisition. OCT imaging acquires deep structural information in a cross-sectional format. Compared with fundus camera-based retinal oximetry, substantial variations in the OCT method for retinal oximetry were found in the present study and the previous study by Kagemann et al. ${ }^{18}$ First, a difference in the wavelengths used for spectral analysis may contribute to this large variation. Spectral imaging systems for the fundus are based on visible light over a wavelength range of 540-605 nm, whereas the SL-UHR-OCT used longer wavelengths of light (central wavelength $840 \mathrm{~nm}$ ). Fundus camera-based oximetry may be affected by deeper layers of the retina, and fundus pigmentation has been found to affect oximetry. ${ }^{14,16}$ The reason for such a large variation could be due to the ability of OCT light to be more deeply penetrable because it has a longer wavelength. This along with the combination of cross-sectional imaging used in the OCT method can display structures such as the outer retina, outer choroid, and deeper layers hidden underneath retinal blood vessels, and can all be included in the analysis. This inclusion may affect the analysis by inducing more background noise, although there did not appear to be background noise due to shadows cast by the vessels (Figure 1C). Further investigation may be required to address this point by using short wavelengths. Secondly, one of the major differences in normal OCT test-retest results is the change in the location of the beam in the pupil and small eye movements. The OCT scan requires more time ( 2.7 seconds) than fundus imagery. No compensation for eye movement was used, which may contribute to the large measurement error. Eye movements or blinking may cause uneven illumination during OCT scanning. Third, analysis of OCT light intensity of the vessels was based on an assumption of a linear relationship between OCT fringe recordings and light intensity absorbed at the vessel. This may warrant further investigation. Last, the small size and gender disparity in this study may limit its generalization to a wider population. 
Our results using this small sample size are generally in agreement with previously reported findings from Kagemann et al. ${ }^{18}$ However, there are some noteworthy differences. Our arterial ODR appeared to be lower than theirs. This may be due to racial differences between the study participants that predispose them to having different fundus pigmentations. ${ }^{16}$ Our healthy control group included 10 Asian subjects, eight Caucasian subjects, and two AfricanAmerican subjects, whereas Kagemann et a ${ }^{18}$ did not report the races of their subjects. Interestingly, we obtained ODRs with smaller standard deviations than those in the report by Kagemann et al. ${ }^{18}$

In conclusion, OCT oximetry for evaluating retinal oxygen saturation was subject to variation, although the averaged measurements in repeated sessions were matched. Further investigation on sources causing variations may improve the method and its use in clinic research. Extending the function of OCT to include measuring oxygen saturation may extend the degree to which OCT is used.

\section{Acknowledgments}

This study was in part supported by research grants from the National Institutes of Health (P30EY014801, R01EY020607, R01EY020607S) and from Research to Prevent Blindness.

\section{Disclosure}

The authors report no conflicts of interest in this work.

\section{References}

1. Tiedeman JS, Kirk SE, Srinivas S, Beach JM. Retinal oxygen consumption during hyperglycemia in patients with diabetes without retinopathy. Ophthalmology. 1998;105:31-36.

2. Schweitzer D, Lasch A, van der Vorst S, et al. Change of retinal oxygen saturation in healthy subjects and in early stages of diabetic retinopathy during breathing of $100 \%$ oxygen. Klin Monbl Augenheilkd. 2007;224:402-410. German.

3. Hickam JB, Sieker HO, Frayser R. Studies of retinal circulation and A-V oxygen difference in man. Trans Am Clin Climatol Assoc. 1959;71:34-44.

4. Hammer M, Vilser W, Riemer T, et al. Diabetic patients with retinopathy show increased retinal venous oxygen saturation. Graefes Arch Clin Exp Ophthalmol. 2009;247:1025-1030.

5. Holekamp NM, Shui YB, Beebe D. Lower intraocular oxygen tension in diabetic patients: possible contribution to decreased incidence of nuclear sclerotic cataract. Am J Ophthalmol. 2006;141:1027-1032.

6. Hardarson SH, Stefansson E. Retinal oxygen saturation is altered in diabetic retinopathy. Br J Ophthalmol. 2012;96:560-563.

7. Lange CA, Stavrakas P, Luhmann UF, et al. Intraocular oxygen distribution in advanced proliferative diabetic retinopathy. Am J Ophthalmol. 2011;152:406-412.

8. Arden GB, Sivaprasad S. Hypoxia and oxidative stress in the causation of diabetic retinopathy. Curr Diabetes Rev. 2011;7:291-304.

9. Olafsdottir OB, Hardarson SH, Gottfredsdottir MS, Harris A, Stefansson E. Retinal oximetry in primary open-angle glaucoma. Invest Ophthalmol Vis Sci. 2011;52:6409-6413.
10. Traustason S, Hardarson SH, Gottfredsdottir MS, et al. Dorzolamide-timolol combination and retinal vessel oxygen saturation in patients with glaucoma or ocular hypertension. Br J Ophthalmol. 2009;93:1064-1067.

11. Hardarson SH, Gottfredsdottir MS, Halldorsson GH, et al. Glaucoma filtration surgery and retinal oxygen saturation. Invest Ophthalmol Vis Sci. 2009;50:5247-5250.

12. Hardarson SH, Stefansson E. Oxygen saturation in branch retinal vein occlusion. Acta Ophthalmol. 2011;90:466-470.

13. Hardarson SH, Stefansson E. Oxygen saturation in central retinal vein occlusion. Am J Ophthalmol. 2010;150:871-875.

14. Beach JM, Schwenzer KJ, Srinivas S, Kim D, Tiedeman JS. Oximetry of retinal vessels by dual-wavelength imaging: calibration and influence of pigmentation. J Appl Physiol. 1999;86:748-758.

15. Hardarson SH, Harris A, Karlsson RA, et al. Automatic retinal oximetry. Invest Ophthalmol Vis Sci. 2006;47:5011-5016.

16. Hammer M, Vilser W, Riemer T, Schweitzer D. Retinal vessel oximetry-calibration, compensation for vessel diameter and fundus pigmentation, and reproducibility. J Biomed Opt. 2008;13:054015.

17. Izhaky D, Nelson DA, Burgansky-Eliash Z, Grinvald A. Functional imaging using the retinal function imager: direct imaging of blood velocity, achieving fluorescein angiography-like images without any contrast agent, qualitative oximetry, and functional metabolic signals. Jpn J Ophthalmol. 2009;53:345-351.

18. Kagemann L, Wollstein G, Wojtkowski M, et al. Spectral oximetry assessed with high-speed ultra-high-resolution optical coherence tomography. J Biomed Opt. 2007;12:041212.

19. Harris A, Dinn RB, Kagemann L, Rechtman E. A review of methods for human retinal oximetry. Ophthalmic Surg Lasers Imaging. 2003;34: $152-164$.

20. Jiang H, Abukhalil F, Shen M, et al. Slit-lamp-adapted ultra-high resolution OCT for imaging the posterior segment of the eye. Ophthalmic Surg Lasers Imaging. 2012;43:76-81.

21. Bland JM, Altman DG. Statistical methods for assessing agreement between two methods of clinical measurement. Lancet. 1986;1: 307-310.

22. Cringle SJ, Yu DY. Oxygen supply and consumption in the retina: implications for studies of retinopathy of prematurity. Doc Ophthalmol. 2010;120:99-109.

23. Yu DY, Cringle SJ. Oxygen distribution and consumption within the retina in vascularised and avascular retinas and in animal models of retinal disease. Prog Retin Eye Res. 2001;20:175-208.

24. Stefansson E, Machemer R, de Juan E Jr, McCuen BW, Peterson J. Retinal oxygenation and laser treatment in patients with diabetic retinopathy. Am J Ophthalmol. 1992;113:36-38.

25. Linsenmeier RA, Padnick-Silver L. Metabolic dependence of photoreceptors on the choroid in the normal and detached retina. Invest Ophthalmol Vis Sci. 2000;41:3117-3123.

26. Schweitzer D, Thamm E, Hammer M, Kraft J. A new method for the measurement of oxygen saturation at the human ocular fundus. Int Ophthalmol. 2001;23:347-353.

27. Hammer M, Leistritz S, Leistritz L, Schweitzer D. Light paths in retinal vessel oxymetry. IEEE Trans Biomed Eng. 2001;48:592-598.

28. Palsson O, Geirsdottir A, Hardarson SH, Olafsdottir OB, Kristjansdottir JV, Stefansson E. Retinal oximetry images must be standardized: a methodological analysis. Invest Ophthalmol Vis Sci. 2012;53:1729-1733.

29. Hardarson SH, Basit S, Jonsdottir TE, et al. Oxygen saturation in human retinal vessels is higher in dark than in light. Invest Ophthalmol Vis Sci. 2009;50:2308-2311.

30. Hammer M, Heller T, Jentsch S, et al. Retinal vessel oxygen saturation under flicker light stimulation in patients with non-proliferative diabetic retinopathy. Invest Ophthalmol Vis Sci. 2012;26:4063-4068.

31. Hammer M, Vilser W, Riemer T, et al. Retinal venous oxygen saturation increases by flicker light stimulation. Invest Ophthalmol Vis Sci. 2011;52:274-277.

32. Wojtkowski M. High-speed optical coherence tomography: basics and applications. Appl Opt. 2010;49:D30-D61. 
33. Huang D, Swanson EA, Lin CP, et al. Optical coherence tomography. Science. 1991;254:1178-1181.

34. Jancevski M, Foster CS. Anterior segment optical coherence tomography. Semin Ophthalmol. 2010;25:317-323.

35. Drexler W, Fujimoto JG. State-of-the-art retinal optical coherence tomography. Prog Retin Eye Res. 2008;27:45-88.

36. Enfield J, Jonathan E, Leahy M. In vivo imaging of the microcirculation of the volar forearm using correlation mapping optical coherence tomography (cmOCT). Biomed Opt Express. 2011;2:1184-1193.
37. Vieira S, Corrente JE. Statistical methods for assessing agreement between double readings of clinical measurements. J Appl Oral Sci. 2011;19:488-492.

38. Delori FC. Noninvasive technique for oximetry of blood in retinal vessels. Appl Opt. 1988;27:1113-1125.

39. Erdfelder E, Faul F, Buchner A. GPOWER: A general power analysis program. Behav Res Methods. 1996;28:1-11.
Clinical Ophthalmology

\section{Publish your work in this journal}

Clinical Ophthalmology is an international, peer-reviewed journal covering all subspecialties within ophthalmology. Key topics include: Optometry; Visual science; Pharmacology and drug therapy in eye diseases; Basic Sciences; Primary and Secondary eye care; Patient Safety and Quality of Care Improvements. This journal is indexed on

\section{Dovepress}

PubMed Central and CAS, and is the official journal of The Society of Clinical Ophthalmology (SCO). The manuscript management system is completely online and includes a very quick and fair peer-review system, which is all easy to use. Visit http://www.dovepress.com/ testimonials.php to read real quotes from published authors. 